\title{
What Factors Are Important in Increasing Junior Doctors' Willingness To Provide Palliative Care in Taiwan? An Educational Intervention Study
}

\author{
Chih-Yuan Shih, M.D., Tai-Yuan Chiu, M.D., MHSci, ${ }^{2}$ Long-Teng Lee, M.D., M.P.H., Ph.D., ${ }^{1,2}$ \\ Chien-An Yao, M.D., ${ }^{2}$ Ching-Yu Chen, M.D. ${ }^{2,3}$ and Wen-Yu Hu, R.N., Ph.D. ${ }^{4}$
}

\begin{abstract}
Purpose: To explore the factors that influence the willingness of junior doctors to provide palliative care in future clinical practice and to evaluate the effect of palliative care education in ameliorating these factors.

Methods: A 2-week clinical training course consisting of clinical patient care, multidisciplinary team meetings, home visits, and lecture series was conducted for interns in a palliative care unit of a university hospital. A structured self-report questionnaire was administered before and after the training.

Results: One hundred forty-seven interns were enrolled and completed the questionnaire, which demonstrated significant improvements in knowledge and beliefs toward palliative care after the training $(p<0.001)$. Although the interns' willingness to provide palliative medical care was influenced by relatives' support before the training (odds ratio $[\mathrm{OR}]=3.861,95 \%$ confidence intgerval $[\mathrm{CI}]=1.217-12.243$ ), this relationship vanished after training. A higher willingness to provide home visits was noted in participants who received palliative care education at medical school. In contrast, information received from mass media was shown to be negatively correlated with willingness. After the training, the only independent variable that was positively correlated with interns' willingness to provide home visits was their own beliefs on palliative care $(\mathrm{OR}=1.074,95 \% \mathrm{CI}=1.058-8.089)$.

Conclusions: Educating junior doctors to build positive beliefs toward palliative care is strongly encouraged. Palliative care education contributes to increased junior doctors' willingness toward providing palliative care, which suggests that this kind of training course should be emphasized in medical education.
\end{abstract}

\section{Introduction}

$\mathbf{T}$ AIWAN IS ONE of the fastest aging societies in the world. In 2007, 10\% of Taiwan's 23 million people were over 65 years of age, a number that will likely double in the next 20 years. With the aging Taiwanese population, the health care system will have an increased number of individuals dying of cancer. In 1997, approximately 29,000 Taiwanese died from cancer and this increased to 40,300 in 2007. Because of the heightened need of end-of-life care, regulations for National Health Insurance reimbursement were issued in 2000 to provide inpatient hospice care to patients with terminal cancer. ${ }^{1}$ Currently, there are 37 qualified inpatient units and 64 qualified home care services in Taiwan, but only approximately $17 \%$ of patients with terminal cancer receive palliative care. $^{2}$
Several studies have demonstrated that end-of life educational curricula and clinical training can improve medical students' knowledge and attitude toward palliative care. ${ }^{3-6}$ Those who complete clinical rotations and courses in palliative care feel more comfortable with death and caring for dying patients. ${ }^{5,7}$ Research on residents and fellowships show a similar result. ${ }^{8,9}$ However, most medical students have inadequate palliative care knowledge ${ }^{3}$ and do not receive appropriate end-of-life education. ${ }^{10,11}$ To date, only half of Taiwan's medical schools have compulsory palliative medicine training in their undergraduate program. ${ }^{12}$ Unlike Taiwan, end-of-life medical education has sharply increased in Western countries. Most of the medical schools in the United States report that end-of-life issues are directly addressed in their curricula. ${ }^{13}$ Therefore, education should be one of the critical areas in promoting palliative care.

\footnotetext{
${ }^{1}$ Department of Family Medicine, North Coast Jin-Shan Hospital, Taipei, Taiwan.

${ }^{2}$ Department of Family Medicine, ${ }^{4}$ School of Nursing, College of Medicine and Hospital, National Taiwan University, Taipei, Taiwan.

${ }^{3}$ Division of Gerontology Research, National Health Research Institutes, Taiwan.

Accepted June 3, 2010.
} 
In Taiwan, the internship is the critical time for junior doctors to develop their own beliefs on palliative care. Medical school training in Taiwan is a 7-year program, including 2 years of premedical courses, 2 years of basic medicine, 2 years of clinical medicine, and 1 year of rotating internships at university hospitals. Internships bridge the gap between medical school curriculum and clinical practice. However, there are no formal internship palliative care training programs in Taiwan and the few courses available are elective. A previous study showed that junior and female Taiwanese medical students, as well as those reporting their religion as Buddhist, indicated a stronger willingness to provide palliative care. ${ }^{10}$ Older medical students were also found to correlate with a more positive view of caring for patients with terminal illness. ${ }^{14}$ In order to improve end-of-life care education, interns' willingness to provide palliative care and the related factors must be explored.

Therefore, our study aims to: (1) identify the willingness of interns to provide palliative care in their future clinical practice; (2) determine the factors that might influence this willingness; and (3) measure the improvement of interns' willingness after the 2 weeks of palliative care training.

\section{Methods}

\section{Subjects}

From 2003 to 2005, 147 interns who attended an elective 2week palliative care curriculum within the internship year were recruited at National Taiwan University Hospital. Questionnaires were distributed to the interns at the beginning and at the end of the curriculum. All of them were completed by the participants, themselves.

\section{Description of the Curriculum}

The 2-week curriculum consisted of a lecture series, multidisciplinary team meetings, home visits, and clinical patient care. Senior doctors conducted the lecture series, including orientation of hospice care, initial assessment of patients with terminal cancer, supporting patients and their families, and common symptoms of patients with terminal cancer. The multidisciplinary faculties in the palliative care unit included palliative care physicians, nurses, clinical psychologists, clinical Buddhist chaplains, and social workers. Interns were requested to undertake home visits at least once and provide inpatient care during the 2-week training, which was conducted under the direction and supervision of palliative care faculty physicians.

\section{Measurements}

A questionnaire consisting of five parts was administered to all participants before and after the training. The five parts of the questionnaire included questions on demographic characteristics, knowledge and beliefs on palliative care, as well as subjective norms and willingness to provide palliative care. The entire questionnaire was evaluated by expert opinion of two physicians, two nurses, one psychologist, and one social worker, with a content validity index of 0.93 . Demographic data included age, education, religious beliefs, experience in providing palliative care, source of information on palliative care, and subjective understanding of palliative care. The other four parts of the questionnaire included the following:

1. Knowledge of palliative care: This 30-item measure was designed with careful scrutiny of related literature and the main reference included the PCQN originally developed by Ross et al., ${ }^{15}$ and modified in previous studies. ${ }^{16,17}$ All items were grounded in the investigators' clinical experiences. The scoring system was "true" (1) and "false/unknown" (0).

2. Beliefs on palliative care: This part of the questionnaire examined the perception of interns regarding the benefits and barriers in providing palliative care. ${ }^{18}$ The content of this measure included 20 items that were scored by using the 5-point Likert scale, from "strongly disagree" (1) to "strongly agree" (5). Bartlett's test of sphericity (BT) and the Kaiser-Meyer-Olkin (KMO) test were administrated and resulted in a BT value of 1511.28 (statistical significance: 0.000 ) and a KMO value of 0.78 , respectively. The draft items were analyzed using principal component factor analysis followed by orthogonal varimax rotation. Finally, the beliefs measure was constructed using benefits ( 9 items) and barriers (11 items) perceived by the physicians when taking care of patients with terminal cancer.

3. Subjective norms: This part was comprised of both "perceived beliefs of significant others' opinions" and "the motivation to comply with significant others' opinions" in providing palliative care. A 5-point Likert scale, from "strongly unaffected" (1) to "strongly affected" (5), was used in the 6-item measures (i.e., influences by spouses, sons, daughters, colleagues, friends, or others). The Cronbach $\alpha$ value was 0.70 .

4. Willingness: This part explored the interns' willingness (yes or no) to provide palliative care services in clinical practice if they encountered a patient with terminal cancer. The contents of palliative care services included providing information about palliative care resources, referring patients to the palliative care units, medical care and prescription, home visits, phone visits, and bereavement care.

\section{Statistical analysis}

The SPSS 12.0 statistical software package (SPSS, Chicago, IL) was used for the analysis. First, a frequency distribution was used to describe the demographic data and the distribution of each variable. Mean values and standard deviations were used to analyze the degree of variation in the knowledge and beliefs on palliative care. Paired $t$ test examined the differences in palliative knowledge and beliefs on pretest and posttest assessments. Factors that significantly influence willingness toward providing palliative care were assessed with univariate analysis. Backward stepwise logistic regression analysis was used to determine the key variables that influence the willingness. A $p$ value $<0.05$ was considered statistically significant.

\section{Results}

\section{Demographic characteristics}

Demographic characteristics of the participants are presented in Table 1. A total of 147 interns completed the 
Table 1. Demographic Characteristics OF INTERNS $(N=147)$

\begin{tabular}{|c|c|c|}
\hline Variable & $\mathrm{n}$ & $(\%)$ \\
\hline \multicolumn{3}{|l|}{ Gender } \\
\hline Male & 110 & 74.8 \\
\hline Female & 37 & 25.2 \\
\hline \multicolumn{3}{|l|}{ Religious beliefs } \\
\hline None & 69 & 46.9 \\
\hline Folk religion & 27 & 18.4 \\
\hline Buddhist & 25 & 17.0 \\
\hline Taoist & 9 & 6.1 \\
\hline Christian & 16 & 10.9 \\
\hline \multicolumn{3}{|c|}{ Experience in caring for terminal cancer patients } \\
\hline No & 116 & 78.9 \\
\hline Yes & 30 & 21.1 \\
\hline \multicolumn{3}{|c|}{ Family or friends have received palliative care } \\
\hline No & 141 & 95.9 \\
\hline Yes & 6 & 4.1 \\
\hline \multicolumn{3}{|l|}{ Ever get information on palliative care } \\
\hline Yes & 123 & 83.7 \\
\hline No & 24 & 6.3 \\
\hline \multicolumn{3}{|l|}{ Sources of information } \\
\hline School curriculum & 129 & 87.8 \\
\hline Medical staff & 47 & 32.0 \\
\hline Newspapers/magazines & 36 & 24.5 \\
\hline Periodicals or books & 33 & 22.4 \\
\hline Mass media & 27 & 18.4 \\
\hline Related seminars & 16 & 10. \\
\hline Bulletins in hospital & 16 & 10.9 \\
\hline In-service education & 12 & 8.2 \\
\hline Friends & 12 & 8.2 \\
\hline \multicolumn{3}{|l|}{ Subjective understanding of palliative care } \\
\hline Very clearly & 5 & 3.4 \\
\hline A little & 119 & 81.0 \\
\hline Hearing about but do not understand & 23 & 15.6 \\
\hline
\end{tabular}

questionnaires before and after the training, resulting in a $100 \%$ response rate. The median age was 25 years and the majority of students were male $(74.8 \%) ; 18.5 \%$ of the students considered themselves believing in folk religion and $17.0 \%$ were Buddhist. Most of the interns had no experience in caring for patients with terminal cancer. Main sources of palliative care information were school curriculum and medical staff.

\section{Knowledge of palliative care}

Interns had a $10 \%$ absolute improvement in their palliative care knowledge score, with accuracy rates of $74 \%$ and $84 \%$ before and after the training, respectively $(p<0.001)$. Participants had a significant improvement in 14 questions, such as "Drug addiction is a major problem when morphine is used on a long-term basis for the management of pain" and "During the terminal stages of an illness, drugs that can cause respiratory depression are appropriate for the treatment of severe dyspnea."

Particularly low scores were noted in "The provision of palliative care requires emotional detachment" and "The use of placebos is appropriate in the treatment of some types of pain."

\section{Beliefs on palliative care}

The mean score of beliefs toward palliative care improved after training ( 3.78 versus 4.0 , range, $1-5, p<0.001$ ). The two subconcepts of beliefs included: "benefits" and "barriers" (inverse counting) in providing palliative care, with mean scores of 4.29 and 3.36 before training, respectively. These results showed positive beliefs among interns toward providing palliative care before training. The items with a lower score in perceived barriers about providing palliative care were "should face the situation of patients suffering and dying," "makes me feel helpless," and "feels more about the meaningless of life and inability to help."

After the 2-week rotation, significant improvement was noted in all of the "barriers" items (mean score $=3.66$, $p<0.01$ ), except "should face the situation of patients suffering and dying" (Table 2).

\section{Willingness to provide palliative care}

Over $90 \%$ of the interns expressed a willingness to provide palliative care in future clinical practice if they encountered patients with terminal cancer (Table 3 ). The majority was willing to refer patients with terminal cancer to a palliative care unit $(90.4 \%)$, followed by providing medical care and home visits.

The analysis of "willingness to provide palliative care" using the McNemar test showed that interns had a significant improvement in three items after training, including "provide information about palliative care resources" $(p<0.001)$, "refer patients with terminal cancer to a palliative care unit" $(p<0.05)$, and "provide medical care" $(p<0.01)$.

\section{Factors influencing willingness}

Results of the stepwise logistic regression analysis are presented in Table 4. While other variables remained unchanged, "relatives' support" and "willingness to provide medical care" were positively correlated before training $(\mathrm{OR}=3.861,95 \% \mathrm{CI}=1.217-12.243, p<0.05)$. However, this correlation vanished after training.

Prior to training, "subjective norm" and "willingness to provide home visits" were positively correlated $(\mathrm{OR}=1.361$, $95 \% \mathrm{CI}=1.081-1.714, p<0.01)$. Interns who perceived themselves to have "a little" understanding of palliative care had a higher willingness to provide home visits than those who had a perceived "very clear" understanding $(\mathrm{OR}=17.974,95 \% \mathrm{CI}=1.780-181.498, p<0.05)$. Interns who received information from school demonstrated a higher willingness to provide home visits. However, a lower willingness was noted in interns who received information from mass media $(\mathrm{OR}=0.234,95 \% \mathrm{CI}=0.088-0.627, p<0.01)$.

After the 2-week training, significant factors influencing the "willingness to provide home visits" were tested by stepwise logistic regression analysis. "Beliefs" was the only factor that was positively correlated with the "willingness to provide home visits."

\section{Discussion}

To our knowledge, this study is one of the first in the AsiaPacific region to investigate junior doctors' willingness to provide palliative care and the associated influencing factors. Prior to training, interns' willingness was positively correlated with relatives' support and medical school education, and negatively influenced by information from mass media. Belief was the only factor that was positively correlated with 
Table 2. Beliefs of Interns Regarding Palliative Care

\begin{tabular}{|c|c|c|c|}
\hline & Pretest & Posttest & $\mathrm{p}$ value \\
\hline \multicolumn{4}{|l|}{ Benefits } \\
\hline 1. Able to promote life quality and keep patient's dignity & 4.43 & 4.50 & 0.09 \\
\hline 2. Enable the patient to die peacefully and have a good death & 4.33 & 4.48 & $0.00^{\mathrm{a}}$ \\
\hline 3. Relieve pain and other symptoms & 4.31 & 4.51 & $0.00^{\mathrm{a}}$ \\
\hline 4. Provide care and companionship by medical team & 4.21 & 4.44 & $0.00^{\mathrm{a}}$ \\
\hline 5. Provide emotional support & 4.20 & 4.37 & $0.00^{\mathrm{a}}$ \\
\hline 6. Prepares for dying & 4.23 & 4.33 & 0.10 \\
\hline 7. Able to have family support & 4.63 & 4.42 & 0.56 \\
\hline 8. Respect for patient's religion and burial rites & 4.20 & 4.33 & $0.02^{\mathrm{b}}$ \\
\hline 9. Help to die at home & 4.11 & 4.38 & $0.00^{\mathrm{a}}$ \\
\hline Total & 4.29 & 4.42 & $0.03^{\mathrm{b}}$ \\
\hline \multicolumn{4}{|l|}{ Barriers (inverse counting) } \\
\hline 1. Make me feel helpless & 2.48 & 2.73 & $0.00^{\mathrm{a}}$ \\
\hline 2. Afraid of visiting terminal patients & 3.24 & 3.59 & $0.00^{\mathrm{a}}$ \\
\hline 3. Influences normal medical activities & 3.31 & 3.58 & $0.00^{\mathrm{a}}$ \\
\hline 4. Give up on patients & 3.55 & 3.90 & $0.00^{\mathrm{a}}$ \\
\hline 5. No active treatment and only awaits death & 3.56 & 3.96 & $0.00^{\mathrm{a}}$ \\
\hline 6. Patients feel abandoned & 3.65 & 4.03 & $0.00^{\mathrm{a}}$ \\
\hline 7. Makes patients feel hopeless & 3.67 & 4.04 & $0.00^{\mathrm{a}}$ \\
\hline 8. No aggressive treatment for physical symptoms & 4.03 & 4.28 & $0.00^{\mathrm{a}}$ \\
\hline 9. Should face the situation of patients suffering and dying & 2.31 & 2.50 & 0.07 \\
\hline 10. Feels more about the meaningless of life and inability to help & 2.86 & 3.07 & $0.03^{\mathrm{b}}$ \\
\hline 11. Shorten patient's life just like euthanasia & 4.26 & 4.54 & $0.00^{\mathrm{a}}$ \\
\hline Total & 3.36 & 3.66 & $0.00^{\mathrm{a}}$ \\
\hline
\end{tabular}

${ }_{\mathrm{b}}^{\mathrm{a}} p<0.001$.

$\mathrm{b}_{p}<0.05$.

the willingness to provide home visits after training. This study demonstrates that the interns' knowledge of, positive beliefs regarding, and the perceived willingness to provide palliative care improved significantly after the training.

As the results reveal, approximately one third of the interns had inadequate knowledge about opioid use. Because pain and dyspnea are common symptoms in patients with terminal cancer, ${ }^{19}$ and opioids are the major medications for symptom control, $^{20,21}$ this knowledge should be reinforced in medical education. A number of international organizations have advised against the use of placebo substitution, ${ }^{22}$ which has been widely recognized as being unethical and potentially harmful. However, $90 \%$ of interns agreed with using placebo for the management of cancer pain and the accuracy rate was only $24 \%$ after training. In Taiwan, traditional cultural values of stoicism and a rare expression of true feelings lead patients

TABle 3. Interns' Willingness To Provide Palliative Care (\%)

\begin{tabular}{lrrr}
\hline & Pretest & Posttest & p value \\
\hline No & 6.1 & 2.7 & 0.180 \\
Yes & 93.8 & 97.2 & \\
$\quad$ Provide information on & 61.9 & 94.1 & $<0.001$ \\
palliative care resources & & & \\
Refer to palliative care unit & 90.4 & 95.2 & $<0.05$ \\
Provide medical care & 83.0 & 90.5 & $<0.01$ \\
Provide home visits & 67.3 & 73.5 & 0.151 \\
Provide phone visits & 68.0 & 72.1 & 0.377 \\
Provide bereavement care & 64.6 & 71.4 & 0.100 \\
\hline
\end{tabular}

with cancer to believe that enduring pain is necessary. ${ }^{23}$ This finding implies the need to emphasize the correct knowledge of pain control in future medical education.

After training, the only significant variable that was positively correlated with the willingness to provide home visits was "beliefs." Taiwanese attitudes toward end-of-life decision making can be understood through the lens of values from traditional religions. ${ }^{24}$ In Taiwan, among those who reported religious beliefs, $61.6 \%$ believe in Buddhism, Taoism, and Confucianism while $36.4 \%$ were Christians and Catholics. ${ }^{25}$ In addition to organized religions, approximately $80 \%$ of the Taiwanese also believe in traditional folk religions, which include some aspects of shamanism, ancestor worship, and animism. Such folk religions may overlap with an individual's belief in Taoism, Confucianism or Buddhism. ${ }^{26}$ In the Taiwanese elderly, Taoist philosophy of natural harmony and flowing with the nature is the most popular view toward life and death. ${ }^{27}$ In contrast, caring for patients with terminal cancer might be viewed as treatment failure and hopelessness in junior doctors and cause apprehension in visiting terminal patients. However, hope at the end of life can come in various forms: comfort, dignity, or intimacy. ${ }^{28}$ By making interns realize that the poor prognosis in palliative care is not equal to hopelessness, their positive beliefs toward palliative care can be enhanced. After training, the item of "should face the situation of patients suffering and dying" did not improve significantly, but "afraid of visiting the terminal patients" improved. This may be because interns understood the needs of patients with terminal cancer better and learned how to accommodate them. Thus, this demonstrates that interns can overcome their fear of facing suffering and death. 
Table 4. Significant Influencing Factors of Intern's Willingness To Provide Palliative Care by Submodels

\begin{tabular}{|c|c|c|c|c|}
\hline \multirow[b]{2}{*}{ Predicting variables } & \multicolumn{3}{|c|}{ Willingness/no willingness } & \multirow[b]{2}{*}{$95 \% \mathrm{CI}$ of $\mathrm{OR}$} \\
\hline & $\beta$ & S.E. & $O R$ & \\
\hline \multicolumn{5}{|l|}{ Submodel 1: Provide medical care } \\
\hline \multicolumn{5}{|l|}{ Before training } \\
\hline Relatives' support & 1.351 & 0.589 & $3.861^{\mathrm{b}}$ & $(1.217-12.243)$ \\
\hline A little understanding of palliative care ${ }^{a}$ & 1.861 & 0.983 & 6.431 & $(0.936-44.192)$ \\
\hline After training & - & - & - & \\
\hline \multicolumn{5}{|l|}{ Submodel 2: Provide home visits } \\
\hline \multicolumn{5}{|l|}{ Before training } \\
\hline Subjective norm & 0.308 & 0.118 & $1.361^{\mathrm{c}}$ & $(1.081-1.714)$ \\
\hline A little understanding of palliative care ${ }^{a}$ & 2.889 & 1.180 & $17.974^{\mathrm{b}}$ & $(1.780-181.498)$ \\
\hline Source of information (School) & 1.256 & 0.593 & $3.511^{\mathrm{b}}$ & $(1.099-11.216)$ \\
\hline Source of information (Mass media) & -1.451 & 0.502 & $0.234^{\mathrm{C}}$ & $(0.088-0.627)$ \\
\hline \multicolumn{5}{|l|}{ After training } \\
\hline Beliefs & 1.074 & 0.519 & $2.926^{\mathrm{b}}$ & $(1.058-8.089)$ \\
\hline
\end{tabular}

Interns' willingness to provide palliative medical care was affected by "relatives' support" before training. However, relatives of physicians in Taiwan might have negative perspectives toward palliative care. The Confucius culture emphasizes that the family is the original source of everything, and family values are emphasized in this traditional Chinese cultural background. ${ }^{29}$ This is why Asians are likely to have a son as the medical decision-maker. ${ }^{30}$ In Asian countries, disagreements between a patient and his or her family about end-of-life care may result in medical professionals who too often follow opinions of patients' family members more than those of the patients. ${ }^{31,32}$ Moreover, Confucianism regards "Hsiao" (filial piety) as one of the key values necessary in maintaining social stability, ${ }^{24}$ and the family members who sign a do-not-resuscitate (DNR) might be viewed as abandoning the loved one. ${ }^{30}$ Transforming people's traditional conceptual frameworks that regard sending the dying loved ones to hospice as abandonment or an unfilial behavior is one of the keys to facilitating acceptance of palliative care in Asian countries. These factors make choosing hospice palliative care difficult in Taiwan. ${ }^{33}$ After training, the influence of "relatives' support" was removed, therefore implying that interns' willingness was independent from external factors. This finding might be explained by the fact that interns' perceived positive beliefs were enhanced after palliative care training.

Palliative home care is important for strengthening the continuity of care for terminal cancer patients. ${ }^{34}$ The old Chinese saying "Luo Yeh Guei Gen" expresses the traditional belief in a good death and that dying at home is as natural as the leaves fall down to the ground. Dying at home has a special cultural meaning both for Chinese patients and their families. ${ }^{35}$ Although studies demonstrate that most patients with cancer prefer to receive terminal care and die at home, ${ }^{36}$ the majority of cancer deaths still occur in hospital. ${ }^{37}$ In Taiwan, transferring patients from the hospital to their home is also difficult. According to a previous multicenter study, in palliative care, place of care is the most frequent encountered ethical dilemma. ${ }^{38}$ Therefore, the willingness of physicians to provide home visits in future clinical practice is important in enhancing the quality of palliative care. Interns' willingness to provide home visits improved after training, but the change was not significant. One explanation is that most of the participants experienced clinical practice within the palliative care unit and might have relatively little experience with home visits. Moreover, 2 weeks of rotation may be too short to let interns realize the benefit of continuing palliative care.

Interns who perceived themselves as understanding information on palliative care "very clearly" had a lower willingness to provide home visits than those with "a little" understanding. The trend was not statistically significant, which might be interpreted as a wrong perception of understanding information "very clearly." Moreover, interns who received information from the mass media showed a lower willingness to provide palliative care while interns who received information in school had a higher willingness. Inadequate information from mass media might focus on the suffering of patients with terminal cancer but rarely provides information on clinical care. In Taiwan, the public is reluctant to talk or think about death, preferring not to consider death until it occurs. Thoughts or conversations about a premature death is ill favored and in that sense people would see it as a taboo. $^{27}$ This may diminish interns' willingness to provide palliative care. Instead of this, end-of-life curriculum in medical school could provide the correct concepts with positive impact on medical students. ${ }^{4}$ To enhance physicians' willingness to provide palliative care, presenting correct concepts and knowledge of palliative care through medical school education should be emphasized.

There are some limitations in this study. First, the training program was elective and nonparticipants were not recruited. Interns who joined the training course might have better knowledge and a higher willingness to provide palliative care. However, there were no differences in age and gender distribution between the participants and the entire cohort. Second, this study was conducted using a self-reporting questionnaire. The results might be overestimated because of the interns' tendency to report beliefs and willingness being viewed as appropriate by the supervisor. In addition, some 
factors that could have an effect on the willingness to provide palliative care might not have been considered in the questionnaire. Nonetheless, although it was a structured questionnaire, we were able to examine a large number of variables and interns were free to express their feelings and beliefs. Third, the adaptation of the results to other countries is a concern as the palliative care models might vary by country. However, we believe that the core values and philosophies of palliative care training should be the same for each country.

In conclusion, educating junior doctors in building positive beliefs toward palliative care is strongly encouraged. Prospective research is required to examine the influence of interns' beliefs and willingness on their future clinical practice. A randomized controlled design is also warranted to explore the effect of end-of-life training on this willingness. Our study suggests that this kind of training course should be emphasized in medical education.

\section{Acknowledgments}

The authors are indebted to the faculties of the Department of Family Medicine, National Taiwan University Hospital, and also Ms. B.Y. Kuo, and Ms. Y.C. Lin for the assistance in preparing the manuscript.

\section{Author Disclosure Statement}

No competing financial interests exist.

\section{References}

1. Tang ST, Chen ML, Huang EW, Koong SL, Lin GL, Hsiao SC: Hospice utilization in Taiwan by cancer patients who died between 2000 and 2004. J Pain Symptom Manage 2007;33:446-453.

2. Chuang RB, Lee IF, Chiu TY, Wang JZ, Lai YL, Hsiao SC, Hsu TH: A preliminary experience of hospice shared-care model in Taiwan [in Chinese]. Taiwan J Hosp Palliat Care 2005;10:234-242.

3. Chang HH, Hu WY, Tsai SS, Yao CA, Chen CY, Chiu TY: Reflections on an end-of-life care course for preclinical medical students. J Formos Med Assoc 2009;108:636-643.

4. Tsai SS, Hu WY, Chang HH, Chang SC, Chen CY, Chiu TY: Effects of a multimodule curriculum of palliative care on medical students. J Formos Med Assoc 2008;107:326-333.

5. Fraser HC, Kutner JS, Pfeifer MP: Senior medical students' perceptions of the adequacy of education on end-of-life issues. J Palliat Med 2001;4:337-343.

6. Ross DD, Shpritz D, Hull MM, Goloubeva O: Longterm evaluation of required coursework in palliative and end-of-life care for medical students. I Palliat Med 2005;8: 962-974.

7. Kaye J, Gracely E, Loscalzo G: Changes in students' attitudes following a course on death and dying: A controlled comparison. J Cancer Educ 1994;9:77-81.

8. Burge F, McIntyre P, Kaufman D, Cummings I, Frager G, Pollett A: Family Medicine residents' knowledge and attitudes about end-of-life care. J Palliat Care 2000;16:5-12.

9. Pan CX, Carmody S, Leipzig RM, Granieri E, Sullivan A, Block SD, Arnold RM: There is hope for the future: National survey results reveal that geriatric medicine fellows are welleducated in end-of-life care. J Am Geriatr Soc 2005;53:705710 .
10. Chang YC, Chou HH, Luh DL, Cheng HF, Lai ST, Hu WC, Hung WT, Chen RC, Chou MC: The attitude of medical students in Taiwan toward hospice palliative care. Chung Shan Med J 2003;14:221-229.

11. Ury WA, Berkman CS, Weber CM, Pignotti MG, Leipzig RM: Assessing medical students' training in end-of-life communication: A survey of interns at one urban teaching hospital. Acad Med 2003;78:530-537.

12. Yao CA, Chiu TY, Hu WY, Chen YU: Current state of hospice palliative medical education in developed countries and Taiwan [in Chinese]. Taiwan J Hosp Palliat Care 2004;9:2843.

13. Dickinson GE: A quarter century of end-of-life issues in U.S medical schools. Death Stud 2002;26:635-646.

14. Lloyd-Williams M, Dogra N: Caring for dying patientsWhat are the attitudes of medical students? Support Care Cancer 2003;11:696-699.

15. Ross MM, McDonald B, McGuinness J: The palliative care quiz for nursing (PCQN): The development of an instrument to measure nurses' knowledge of palliative care. J Adv Nurs 1996;23:126-137.

16. Hu WY, Chiu TY, Dai YT, Chang M, Jaing TH, Chen CY: Nurses' willingness and the predictors of willingness to provide palliative care in rural communities of Taiwan. I Pain Symptom Manage 2003;26:760-768.

17. Liu WJ, Hu WY, Chiu YF, Chiu TY, Lue BH, Chen CY, Wakai S: Factors that influence physicians in providing palliative care in rural communities in Taiwan. Support Care Cancer 2005;13:781-789.

18. Nielsen BB, McMillan S, Diaz E: Instruments that measure beliefs about cancer from a cultural perspective. Cancer Nurs 1992;15:109-115.

19. Chiu TY, Hu WY, Chen CY: Prevalence and severity of symptoms in terminal cancer patients: a study in Taiwan. Support Care Cancer 2000;8:311-313.

20. Hu WY, Chiu TY, Cheng SY, Chen CY: Morphine for dyspnea control in terminal cancer patients: Is it appropriate in Taiwan? J Pain Symptom Manage 2004;28:356-363.

21. Thomas JR, von Gunten CF: Clinical management of dyspnea. Lancet Oncol 2002;3:223-228.

22. Nichols KJ, Galluzzi KE, Bates B, Husted BA, Leleszi JP, Simon K, Lavery D, Cass C: AOA's position against use of placebos for pain management in end-of-life care. I Am Osteopath Assoc 2005;105:S2-5.

23. Chiu TY: End-of-life decision making in Taiwan. In: Blank RH, Merrick JC (eds): End-of-Life Decision Making: A CrossNational Study. Cambridge: MIT, 2005, pp. 169-181.

24. Bowman KW, Singer PA: Chinese seniors' perspectives on end-of-life decisions. Soc Sci Med 2001;53:455-464.

25. The Department of Statistics, Ministry of the Interior, R.O.C. (2008). General condition of temples, churches in statistical yearbook of interior. http://sowf.moi.gov.tw/stat/year/ list.htm (Last accessed March 1, 2010).

26. The Bureau of Democracy, Human Rights, and Labor, USA. (2009). Annual Report on International Religious Freedom (East Asia and Pacific Section). www.state.gov/g/drl/rls/ irf/2009/127269.htm (Last accessed March 1, 2010).

27. Hsin HC, Macer D: Confucian and Taoist influences on the images of life among seniors in Taiwan. Turkiye Klinikleri J Med Ethics 2004;12:211-225.

28. Sullivan MD: Hope and hopelessness at the end of life. Am J Geriatr Psychiatry 2003;11:393-405.

29. Tsai DF: Ancient Chinese medical ethics and the four principles of biomedical ethics. J Med Ethics 1999;25:315-321. 
30. Huang $\mathrm{CH}, \mathrm{HU}$ WY, Chiu TY, Chen CY: The practicalities of terminally ill patients signing their own DNR orders-A study in Taiwan. J Med Ethics 2008;34:336-340.

31. Hu WY, Chiu TY, Chuang RB, Chen CY: Solving familyrelated barriers to truthfulness in cases of terminal cancer in Taiwan. A professional perspective. Cancer Nurs 2002;25: 486-492.

32. Tang ST, Liu TW, Lai MS, Liu LN, Chen CH: Concordance of preferences for end-of-life care between terminally ill cancer patients and their family caregivers in Taiwan. J Pain Symptom Manage 2005;30:510-518.

33. Glass AP, Chen LK, Hwang E, Ono Y, Nahapetyan L: A cross-cultural comparison of hospice development in Japan, South Korea, and Taiwan. I Cross Cult Gerontol 2010;25: 1-19.

34. Hu WY, Chiu TY, Cheng YR, Chuang RB, Chen CY: Why Taiwanese hospice patients want to stay in hospital: Healthcare professionals' beliefs and solutions. Support Care Cancer 2004;12:285-292.

35. Tang ST: Meanings of dying at home for Chinese patients in Taiwan with terminal cancer: A literature review. $\underline{\text { Cancer }}$ Nurs 2000;23:367-370.
36. Townsend J, Frank AO, Fermont D, Dyer S, Karran O, Walgrove A, Piper M: Terminal cancer care and patients' preference for place of death: A prospective study. BMJ 1990;301:415-417.

37. Chen CC, Bai YY, Huang GH, Tang ST: Revisiting the concept of malnutrition in older people. J Clin Nurs 2007;16: 2015-2026.

38. Chiu TY, Hu WY, Cheng SY, Chen CY: Ethical dilemmas in palliative care: A study in Taiwan. J Med Ethics 2000;26: 353-357.

Address correspondence to: Wen-Yu Hu, R.N., Ph.D. School of Nursing

College of Medicine and Hospital National Taiwan University

1 Ren-Ai Road Section 1 Jhongjheng District

Taipei 100

Taiwan

E-mail: weyuhu@ntu.edu.tw 
